\title{
Simultaneous Myopic Defocus for Myopia Control: Effect on Accommodation, Peripheral Refraction and Retinal Image Quality in Non-Presbyopic Patients
}

\author{
Alina Fritschi ${ }^{1}$, Chloe Gerber ${ }^{2}$, Damian Eggler ${ }^{3}$ and Martin Loertscher $4,5, * \mathbb{C}$ \\ 1 Falco-Linsen AG, Talackerstrasse 14, 8274 Tägerwilen, Switzerland; af@falco-linsen.com \\ 2 Spörri Optik, Nidaugasse 70, 2502 Biel, Switzerland; info@spoerrioptik.ch \\ 3 Art of Optic, Stickereistrasse 4, 9320 Arbon, Switzerland; damian.eggler@shark-tech.ch \\ 4 Fachhochschule Nordwestschweiz, Institut für Optometrie Riggenbachstrasse 16, 4600 Olten, Switzerland \\ 5 Pallas Kliniken, Bahnhofplatz 4, 5001 Aarau, Switzerland \\ * Correspondence: martin.loertscher@fhnw.ch; Tel.: +41-62-957-28-64
}

check for

updates

Citation: Fritschi, A.; Gerber, C.; Eggler, D.; Loertscher, M. Simultaneous Myopic Defocus for Myopia Control: Effect on Accommodation, Peripheral Refraction and Retinal Image Quality in Non-Presbyopic Patients. Optics 2021, 2, 200-215. https://doi.org/ 10.3390/opt2040019

Academic Editor:

José-María Sánchez-González

Received: 31 August 2021

Accepted: 27 September 2021

Published: 30 September 2021

Publisher's Note: MDPI stays neutral with regard to jurisdictional claims in published maps and institutional affiliations.

Copyright: (c) 2021 by the authors. Licensee MDPI, Basel, Switzerland. This article is an open access article distributed under the terms and conditions of the Creative Commons Attribution (CC BY) license (https:// creativecommons.org/licenses/by/ $4.0 /)$.

\begin{abstract}
Exposing the retina to a simultaneous myopic defocus is an optical method that has shown a promising effect in slowing the progression of myopia. Optical treatments applying a simultaneous defocus are available in the form of soft contact lenses or multifocal lenses originally designed to correct presbyopia. Orthokeratology is another optical method that slows down the progression of myopia. With orthokeratology, it is hypothesized that a change in peripheral refraction could slow the progression of myopia. We aimed to measure the accommodation response between monofocal and multifocal contact lenses in young subjects. Additionally, we performed a raytracing simulation to visualize the quality of the retinal image and the refractive status in the retinal periphery. The accommodation and pupil size measurements were performed on 29 participants aged $24.03 \pm 2.73$ years with a refractive error (spherical equivalent) of $-1.78 \pm 1.06 \mathrm{D}$. With the multifocal lens in situ, our participants showed less accommodation in comparison to the monofocal contact lens (mean difference, $0.576 \pm 0.36 \mathrm{D}, p>0.001$ ) when focusing on a near target at $40 \mathrm{~cm}$. Pupil size became smaller in both contact lens groups during an accommodation of $0.29 \pm 0.69 \mathrm{~mm}$, $p \leq 0.001$ and $0.39 \pm 0.46 \mathrm{~mm}, p \leq 0.001$ for monofocal and multifocal contact lenses, respectively. The ray-tracing model showed a degradation for central and peripheral vision with the multifocal contact lens. The peripheral refraction was relatively myopic in both contact lens conditions up to $30^{\circ}$. Even if the accommodation ability is without fault, parts of simultaneous myopic defocus are used for the near task. The peripheral refraction in the ray-tracing model was not different between the two contact lenses. This is contrary to the proposed hypothesis that myopic peripheral refraction slows down the progression of myopia in current optical methods.
\end{abstract}

Keywords: myopia control; peripheral refraction; accommodation; image quality; multifocal contact lens; ray tracing; lag of accommodation

\section{Introduction}

The rising prevalence of myopia in children [1-3] is of great concern. Therefore, methods to control and slow the progression of myopia have been developed or are presently under development. Currently, atropine eyedrops are a pharmaceutical therapy that shows promising effects depending on the concentration [4-7]. The effects of atropine are dose-dependent, and low-dose atropine is not efficient in slowing the elongation of the eyes' axial length [8]. With a higher concentration of atropine, the slowing effect increases, but so does the effect of atropine on the ciliary muscle and the sphincter muscle, which causes blurred near vision and photophobia [9]. One way to reduce the progression of myopia seems to be through natural means, such as via frequent exposure to bright natural sunlight while playing outdoors, for example [10]. The effect of being outdoors seems 
to be a stronger factor in slowing myopia progression but with a difference in efficacy between the ethnicities [11]. Based on the optical properties of light, blue light may play a role in slowing myopia progression compared to red light [12]. Optical treatment is based on the assumption of changes in the peripheral retina refraction [13]; such changes are obvious when orthokeratology is used as a method of vision correction [14]. However, the hypothesis that peripheral refraction plays a role in emmetropization is under debate [15]. Another hypothesis regarding optical treatment methods is that exposing the retina to an on-axis simultaneous myopic defocus slows the progression of myopia. This optical method shows good results in slowing the progression of myopia in children [16-20]. On-axis simultaneous myopic defocus is also applied in multifocal contact lenses for the correction of presbyopia $[21,22]$. In presbyopia, the aim of the defocus is as a substitute for the insufficient accommodation. However, myopia control is mainly applied to children who have sufficient accommodation abilities. A study using monovision in children showed that the far-correction eye accommodates normally [22]. Additionally, with soft contact lenses [18] and multifocal orthokeratology [20], accommodation is not highly affected in children when a simultaneous defocus is applied. Apart from a slight image degradation that comes with the use of multifocal optics [23], such optical correction methods are well tolerated. Thus, the question remains of how accommodation is influenced by an on-axis myopic defocus during near tasks. Our aim was to measure the accommodation response in non-presbyopic participants when using a contact lens with a simultaneous myopic defocus of $2.00 \mathrm{dpt}$. Additionally, we performed a ray-tracing simulation with both contact lens types, generating images that showed the image quality for the central vision and peripheral vision up to an angle of $30^{\circ}$.

\section{Materials and Methods}

The study adhered to the tenets of the Declaration of Helsinki, received approval from the Northwestern Switzerland Health Ethics Committee (Approval No. 2019-00329), and was prospectively registered with the National Clinical Trial Registry (BASEC). Participants gave written consent to participate.

To introduce a simultaneous myopic defocus to the retina, we used the contact lens Proclear Multifocal Type " $\mathrm{D}$ " with the distance correction in the center. The same lens was previously used for myopia control [22], and the power profile of the lens was also familiar [24]. The monofocal control lens was Proclear Monofocal. Both contact lenses were made of the same hydrogel material: "omafilcon A".

To test the accommodation response, we compared the objective refraction between a measurement at $40 \mathrm{~cm}$ and a measurement at $1 \mathrm{~m}$. The difference was taken as the amount of accommodation. The measurement was taken using binocular infrared photo retinoscopy (Plusoptix A16, Plusoptix, Nürnberg, Germany) $[25,26]$. The Plusoptix A16 used an infrared measurement beam with a wavelength of $870 \mathrm{~nm}$ and a maximum intensity of $135 \mathrm{~mW} / \mathrm{sr}$. Furthermore, we simulated the optical concept with ray-tracing software to demonstrate the optical results on the retina.

\subsection{Experimental Setup}

The measurement setup was fixed, and was composed of a near target at $40 \mathrm{~cm}$ and a distant target at $6 \mathrm{~m}$ distance from the participant's eye (Figure 1A,B). The binocular retinoscope was placed at a $1 \mathrm{~m}$ distance from the participant. The luminance in the room was kept constant at 140 lux. The measurements were taken in the afternoon between 2:00 and 5:00 pm. 


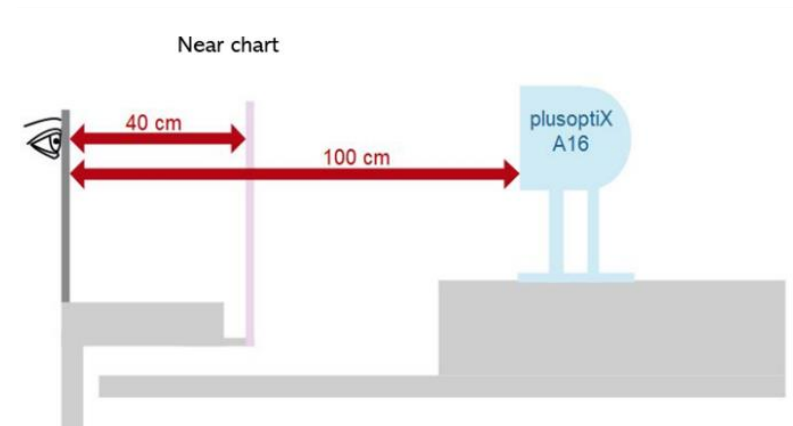

A

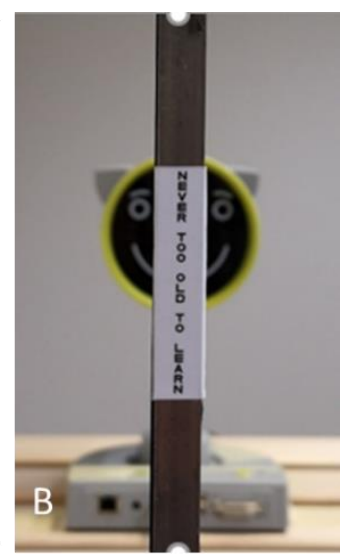

Figure 1. Setup to acquire accommodation data. Both eyes looked through binoculars either into the distance or at the movable near chart. The acquisition of the data with the autorefractor was simultaneous in both eyes under the binocular condition. (A) Setup overview. (B) Movable near target at $40 \mathrm{~cm}$ as seen by the participant.

The accommodation target was a printed text at $40 \mathrm{~cm}$ (VA size 0.2 LogMAR) positioned on the subject's midline in all cases. A similar setup was previously used for another type of open-filed autorefractor [27]. The experimental setup was used as described in Figure 1. The participant wore binoculars, either the Proclear multifocal lens or the Proclear monofocal lens. We took autorefractor measurements when viewing at a distance and at $40 \mathrm{~cm}$. The autorefractor value was transformed to the spherical equivalent. The difference of near value minus distance value was taken as the accommodation. We used a binocular setup; therefore, we took the mean value of both eyes to analyze the accommodation response. In previous validation measures, we did not find a difference between the right and left eyes. The order in which each lens type was worn was randomly generated. The experiment was double-masked, and neither the participant nor the operator at the autorefractor knew which lens was being used at each given time. Additional data measured included pupil size when viewing near and distant targets and changes in interpupillary distance between near and distant targets.

\subsection{Participants}

We included 29 participants in the study.

The inclusion criteria were as follows:

- $\quad$ Aged between 20 and 30 years;

- Refraction error between -0.50 and $-4.00 \mathrm{D}$;

- Maximum astigmatism of $-1.00 \mathrm{D}$;

- Corrected visual acuity of at least LogMAR $0.0(20 / 20)$ or better.

Exclusion criteria were as follows:

- Amblyopia;

- Strabismus;

- Active eye disease that does not allow for wearing contact lenses;

- Pseudophakia.

There were no restrictions regarding gender.

\subsection{Optical Simulation}

To simulate the retinal image through the contact lenses, we used the ray-tracing software OpTaliX OpTaliX-Pro 64-bit V 9.25 (Optenso, Igling, Germany). As a basis eye, we used a modified Gullstrand eye. We fitted the monofocal and multifocal contact lens to the modified Gullstrand eye and generated the point spread function on the retina for distance and near vision. Pupil size and lag of accommodation were incorporated into the model based on the values of our participants. 


\subsection{Statistical Analysis}

Data analysis was carried out with IBM SPSS software, version 25. First, we prepared a descriptive summary of the data. Then, the normality was tested with the Shapiro-Wilk test. When the data followed a normal distribution, a t-test was applied to compare the accommodation data between multifocal contact lenses and monofocal contact lenses. Power calculation showed that 29 participants were required in the accommodation experiment in order to achieve an alpha level of $5 \%$ and a power of $95 \%$; therefore, a significant result was reported when $p \leq 0.05$.

Ray-tracing simulation and image generation were carried out with OpTaliX-Pro 64-bit V 9.25 (Optenso, Igling, Germany).

\section{Results}

\subsection{Accommodation}

In the accommodation experiment, the participants were $24.03 \pm 2.73$ years old with a refractive error of $-1.78 \pm 1.06 \mathrm{D}$. In this experiment, the contact lenses (one-time multifocal and one-time monofocal) were worn binocularly. The data followed a normal distribution. With the multifocal lens in place, the participants used less accommodation. The results (Figure 2) showed a mean difference of $0.576 \pm 0.36 \mathrm{D}, 95 \% \mathrm{CI}(0.43 / 0.71), \mathrm{t} 8.549$, df 28 , $p>0.001$. In Figure 3, the scatter plot showed that less accommodation was needed for a viewing at $40 \mathrm{~cm}$ with the multifocal lens in place.

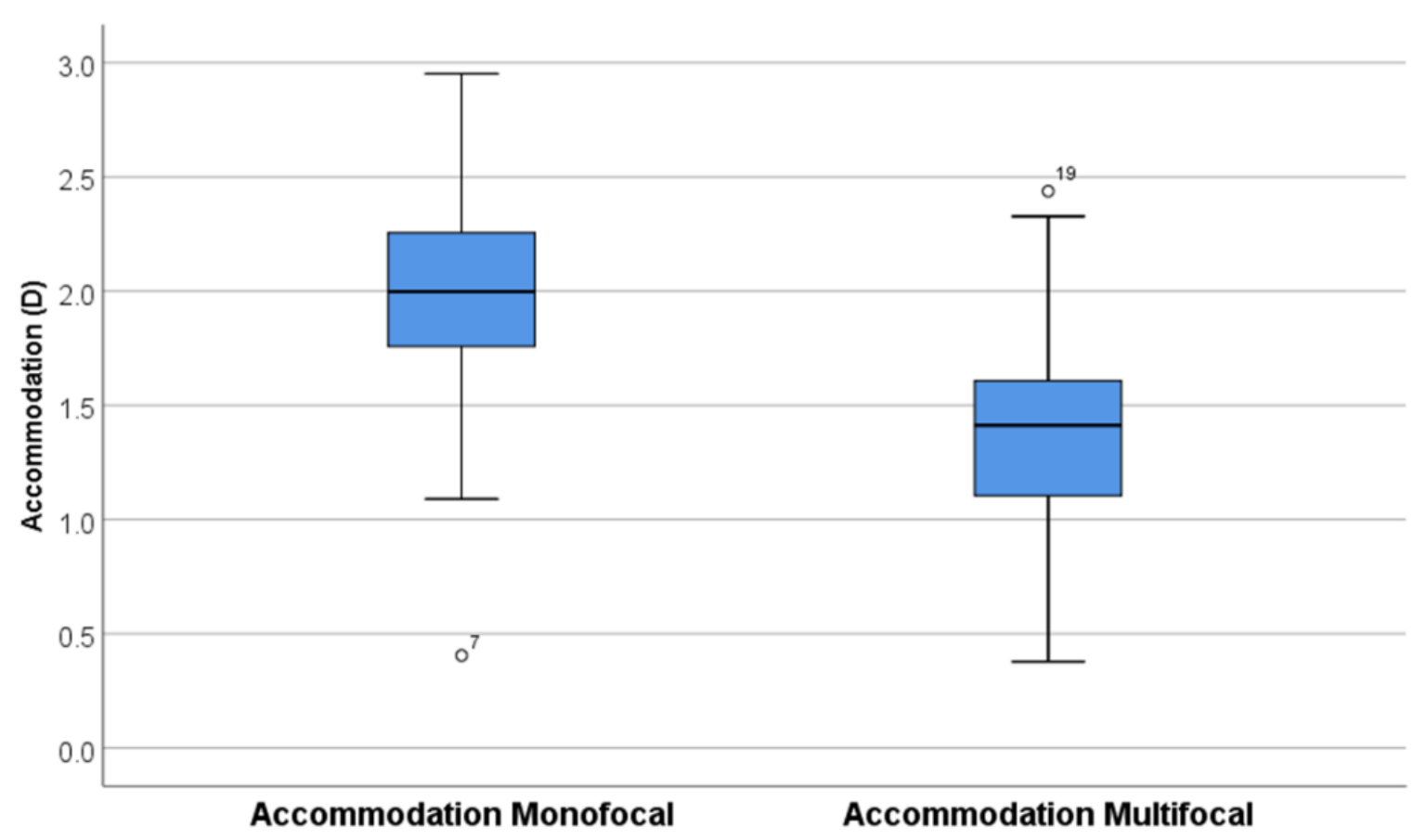

Figure 2. Boxplot of binocular accommodation at $40 \mathrm{~cm}$. 


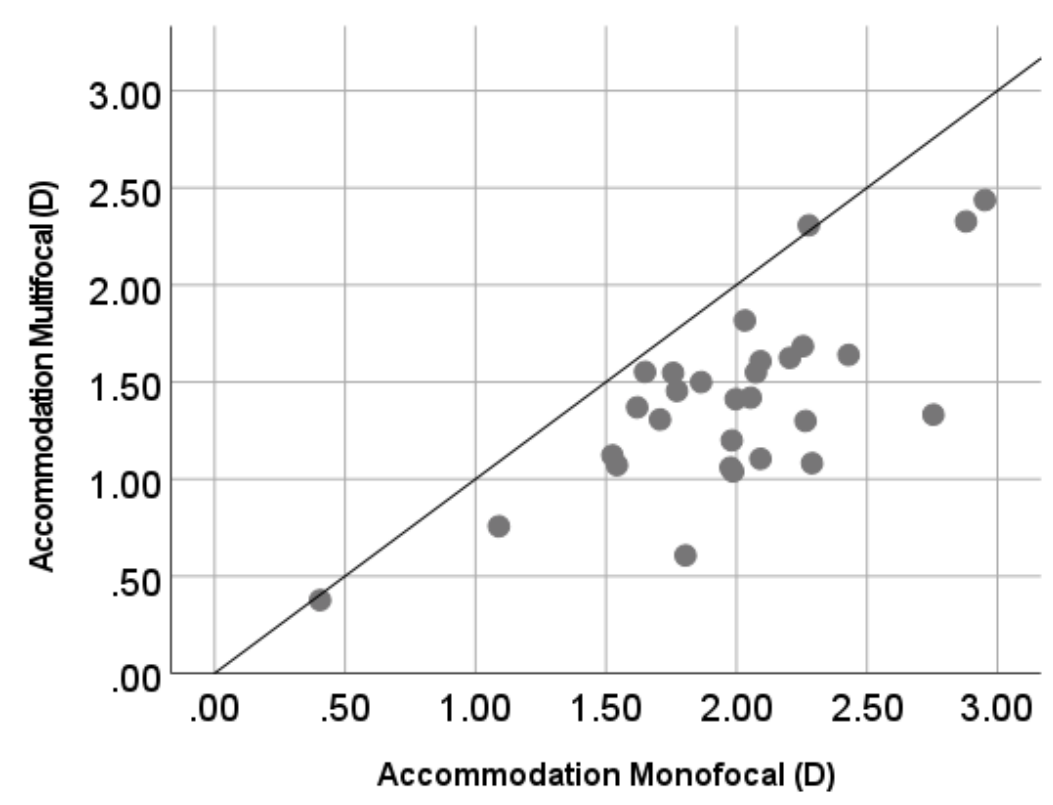

Figure 3. The scatterplot shows that less accommodation was used to focus on a near target at $40 \mathrm{~cm}$ with multifocal contact lenses in place.

\subsection{Pupil Size}

The change in pupil size when changing the focus from the distant to the near target was significant with both types of contact lenses. When wearing monofocal lenses, the pupil diameter became smaller when viewing at $40 \mathrm{~cm}$ with a mean difference of $0.29 \pm 0.69 \mathrm{~mm}$, $95 \%$ CI $(0.03 / 0.55), \mathrm{t} 2.303$, df 28, $p=0.029$. Additionally, with multifocal lenses, pupil size was smaller during the near task, with a mean difference of $0.39 \pm 0.46 \mathrm{~mm}, 95 \% \mathrm{CI}$ $(0.22 / 0.57), \mathrm{t} 4.641, \mathrm{df} 28, p<0.001$. Figure 4 shows that the diameter of the pupil decreased with the increasing accommodation.

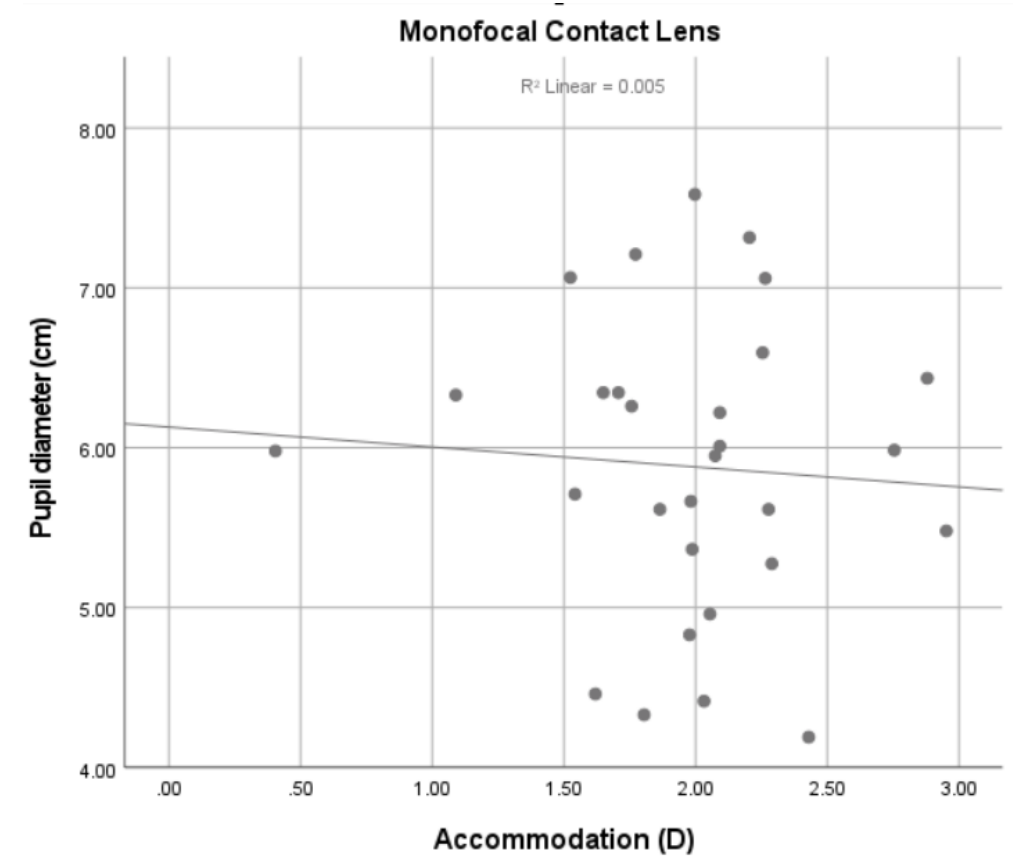

Figure 4. Change of pupil size with accommodation. 


\subsection{Interpupillary Distance}

When changing the gaze from a target at a distance to a nearer target, the eye has to converge. This yoked effect of convergence is visible in a smaller interpupillary distance. This was found in both wearing conditions. Monofocal lenses showed a mean difference of $0.94 \pm 0.25 \mathrm{~mm}, 95 \% \mathrm{CI}(0.84 / 1.04), \mathrm{t} 19.74, \mathrm{df} 28, p<0.001$, while multifocal lenses showed a mean difference of $0.92 \pm 0.20 \mathrm{~mm}, 95 \% \mathrm{CI}(0.83 / 0.99), \mathrm{t} 23.79, \mathrm{df} 28, p<0.001$.

\subsection{Optical Visualization}

To visualize the optical content of our experiment, we carried out optical modeling with our data. We used a ray-tracing model based on the values in Table 1 . The reference wavelength was $546 \mathrm{~nm}$.

Table 1. Dimension of the data used for the ray-tracing model with the software OpTaliX. The complete description of the model is in the supplemental materials.

\begin{tabular}{cc}
\hline Object & Radius (mm) \\
\hline Anterior radius Proclear MF & 9.12 \\
Anterior peripheral radius MF & 8.52 \\
Anterior radius Proclear monofocal & 9.12 \\
Posterior radius MF and monofocal & 8.7 \\
Contact lens central thickness & 0.01 \\
Anterior cornea radius & 8.1 \\
Posterior corneal radius & 6.8 \\
Central corneal thickness & 0.5 \\
Anterior chamber depth & 3.6 \\
Pupil diameter without accommodation & 2.4 \\
Pupil diameter with accommodation & 2.2 \\
Anterior lens radius without accommodation & 10 \\
Posterior lens radius without accommodation & -6.0 \\
Anterior lens radius with accommodation & 9 \\
Posterior lens radius with accommodation & -5.4 \\
Retina radius & -11 \\
Axial length & 27.367 \\
\hline
\end{tabular}

First, we generated a ray-tracing model of the central and peripheral refraction. We simulated the tangential and sagittal lines of focus (Figures 5 and 6 ). We used the refraction data and the accommodation data. Therefore, a lag of accommodation was visible in all the pictures with the model focusing on the near target (Figures 7 and 8). The rays entering the eye from the periphery were simulated from $30^{\circ}$ temporal to $30^{\circ}$ nasal. In both focusing distances (infinity and $40 \mathrm{~cm}$ ), as well as with both contact lenses, a relative myopic defocus compared to the fovea was present. 


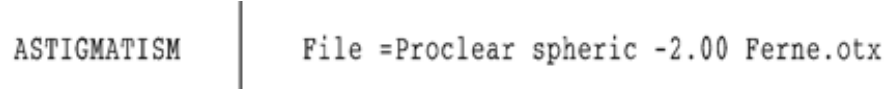

Field-Y

(deg.)

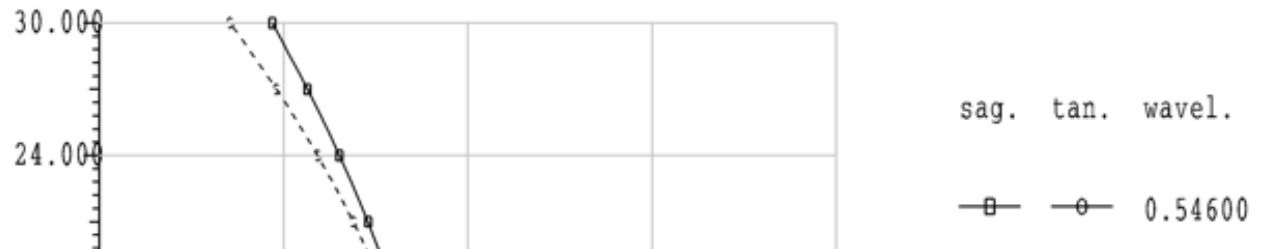

18.0

$$
12.0
$$

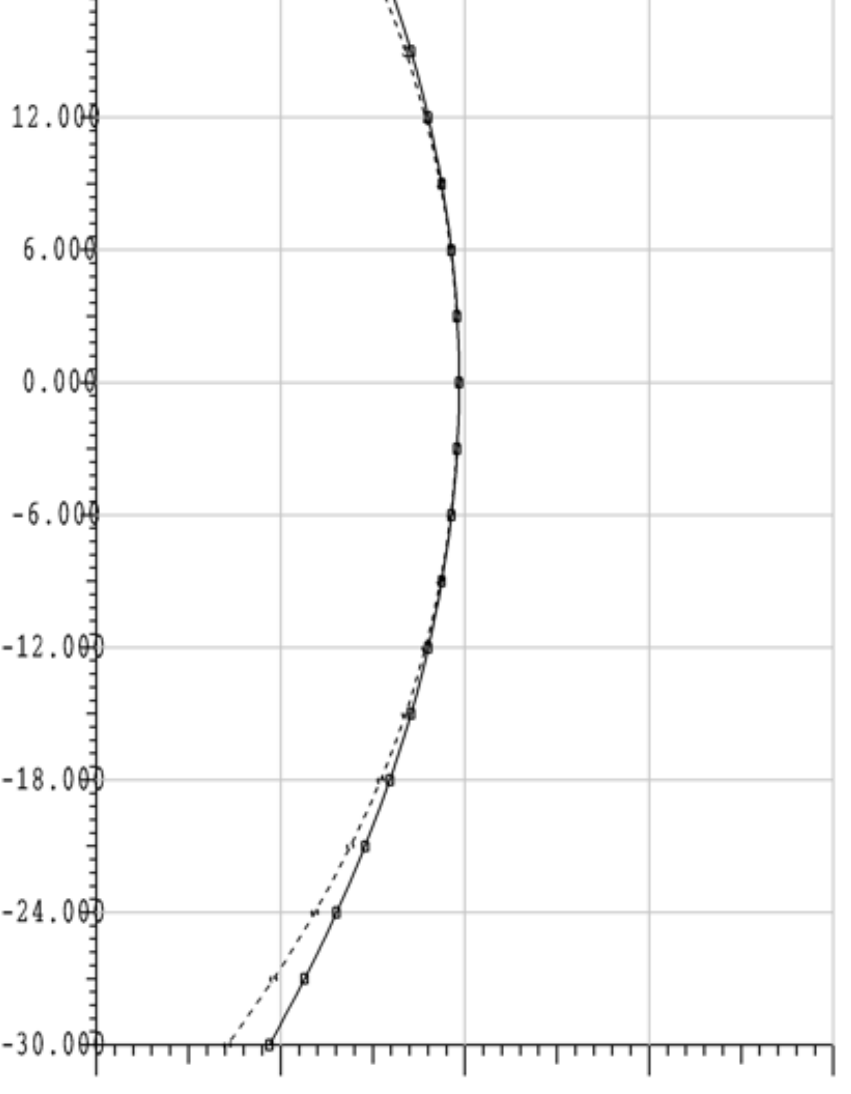

$$
\begin{array}{lllll}
-6.000 & -3.000 & 0.000 & 3.000 & 6.000
\end{array}
$$

Focus (mm)

Figure 5. Peripheral refraction with Proclear monofocal correction $-2.00 \mathrm{D}$ of myopia, viewing distance at infinity: sagittal and tangential focal lines. Within the central $12^{\circ}$ is a plano-refraction; after the central $12^{\circ}$ both focal lines become myopic relative to the center (Fovea). 


\section{Field-Y}

(deg.)
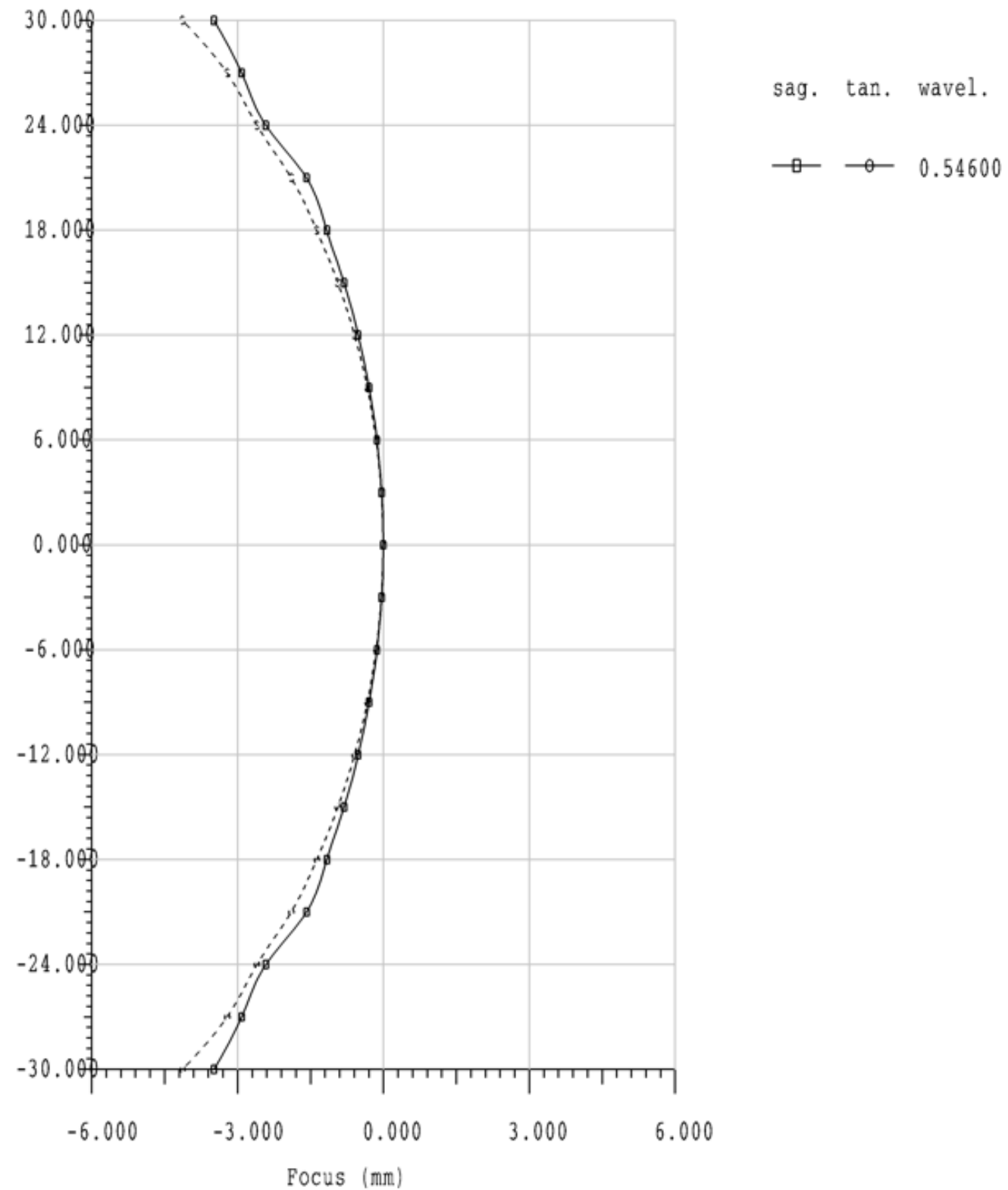

Figure 6. Peripheral refraction with Proclear multifocal correction $-2.00 \mathrm{D}$ of myopia, viewing distance at infinity: sagittal and tangential focal lines. Within the central $12^{\circ}$ is a plano-refraction; after the central $12^{\circ}$ both focal lines become myopic relative to the center (Fovea). 


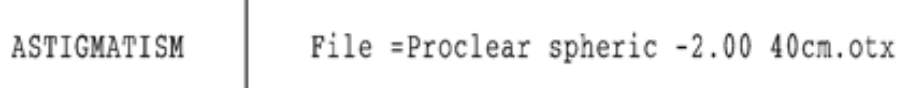

Field-Y

(deg.)
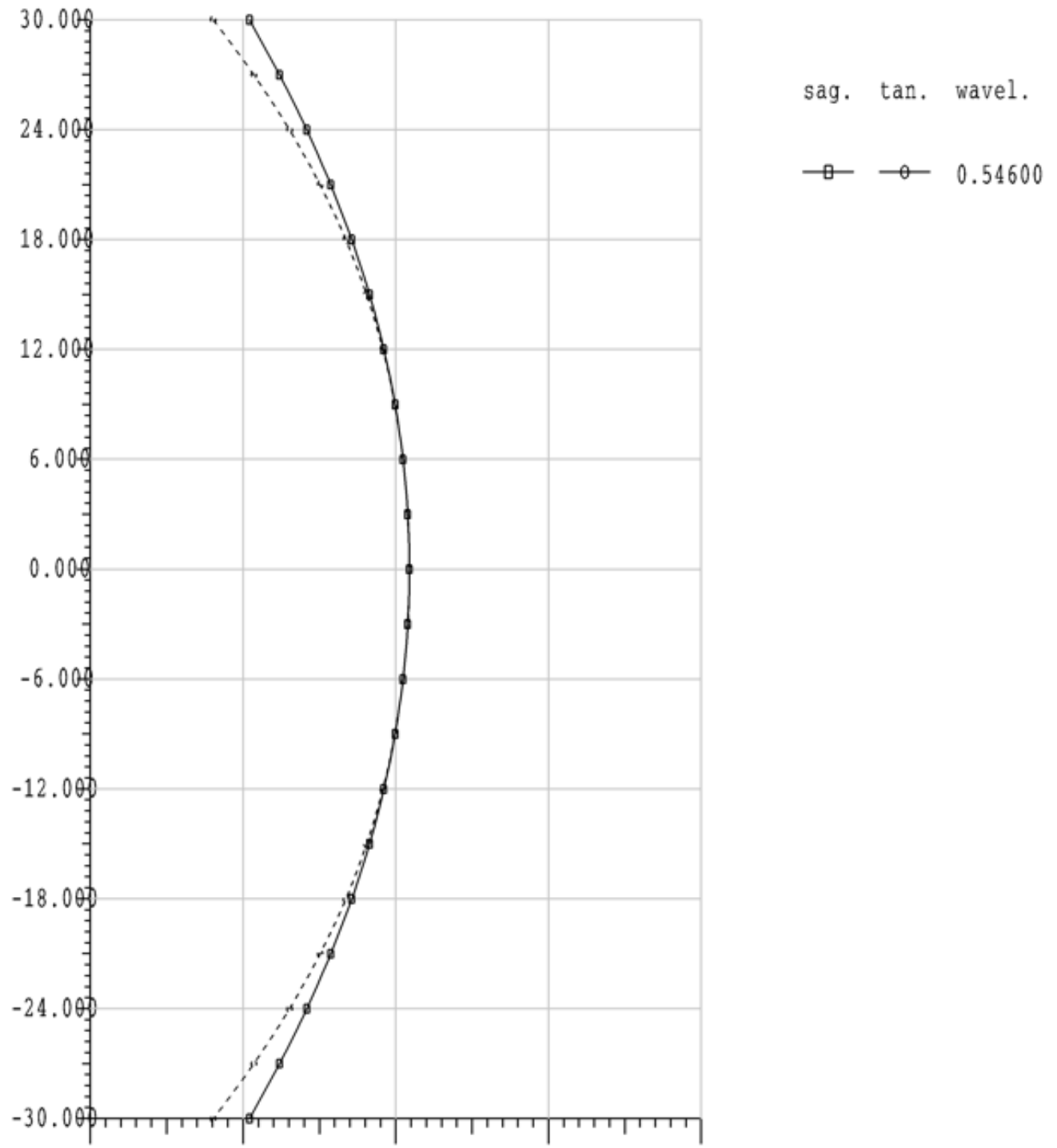

$\begin{array}{llll}-6.000 & -3.000 \quad 0.000 & 3.000 & 6.000\end{array}$

Focus (mm)

Figure 7. Peripheral refraction with Proclear monofocal correction $-2.00 \mathrm{D}$ of myopia, viewing distance at $40 \mathrm{~cm}$ : sagittal and tangential focal lines. Within the central $18^{\circ}$ a lag of accommodation is visible that refers to a hyperopic defocus. Outside the central $18^{\circ}$ both focal lines become myopic relative to the center (Fovea). 
Field-Y

(deg.)

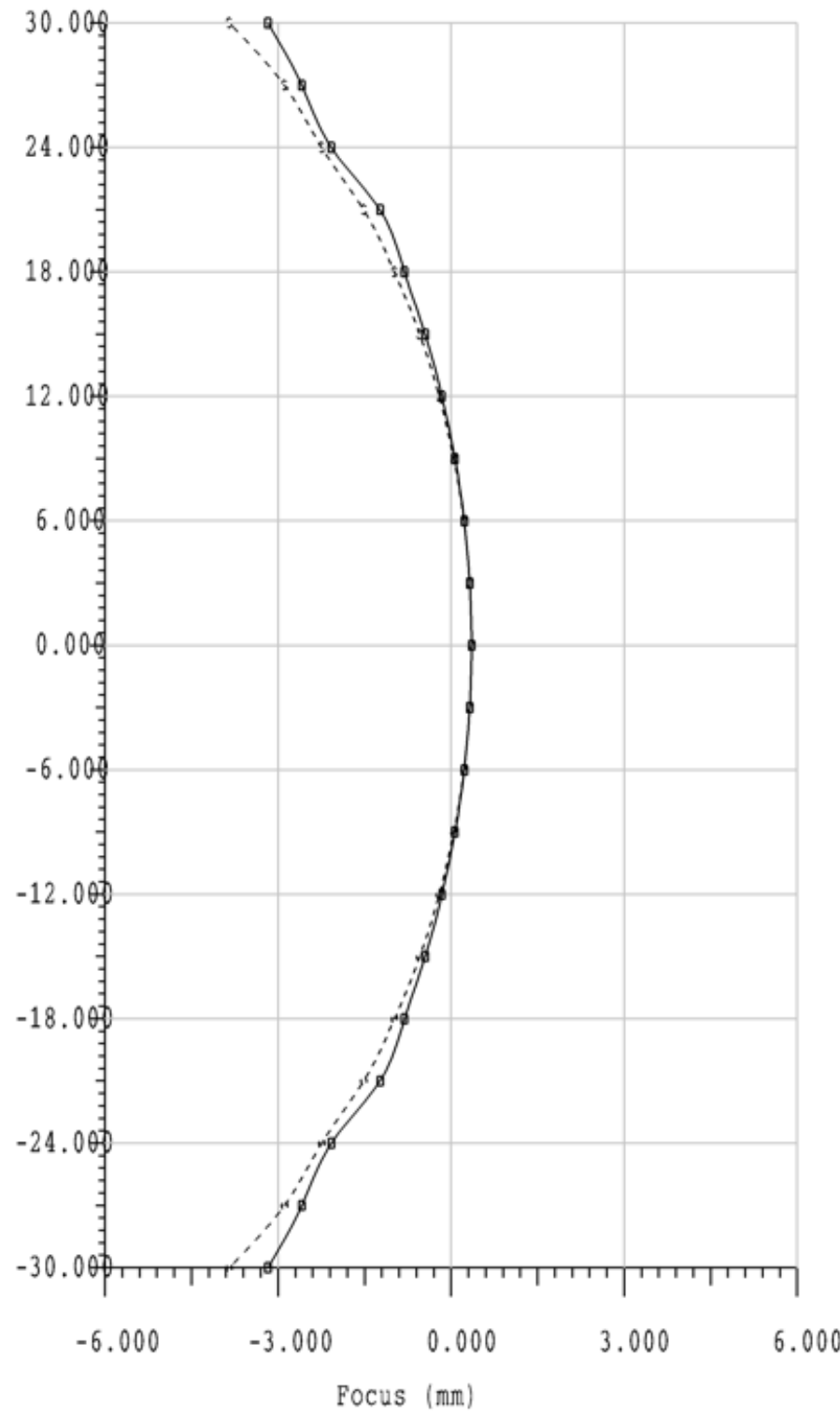

sag. tan. wavel.

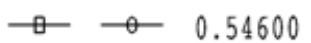

Figure 8. Peripheral refraction with Proclear multifocal correction $-2.00 \mathrm{D}$ of myopia, viewing distance at $40 \mathrm{~cm}$ : sagittal and tangential focal lines. Within the central $18^{\circ}$ a lag of accommodation is visible that refers to a hyperopic defocus. Outside the central $18^{\circ}$ both focal lines become myopic relative to the center (Fovea).

The quality of the retinal image is represented by the computer-generated image of the point spread function. We generated the image for the central foveal image and then in $5^{\circ}$ increments up to $30^{\circ}$ nasal and temporal. We completed this for the Proclear monofocal and multifocal lenses with light rays entering the eye from infinity (Figures 9 and 10) and when focusing on a target at $40 \mathrm{~cm}$. The corresponding Strehl ratio for each eccentricity is in Table 2. 


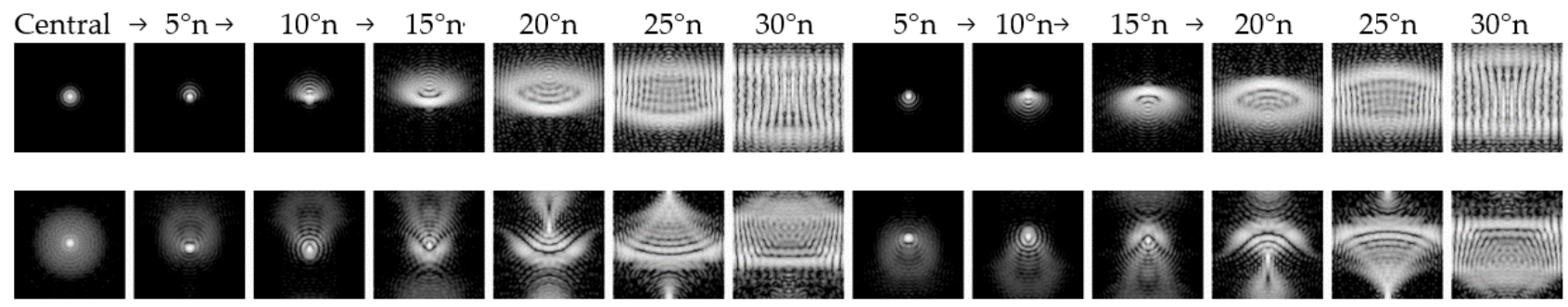

Figure 9. Simulated retinal image quality from the central up to $30^{\circ}$ nasal and temporal. (Top row): Proclear monofocal. (Bottom row): Proclear multifocal. Viewing distance at infinity.
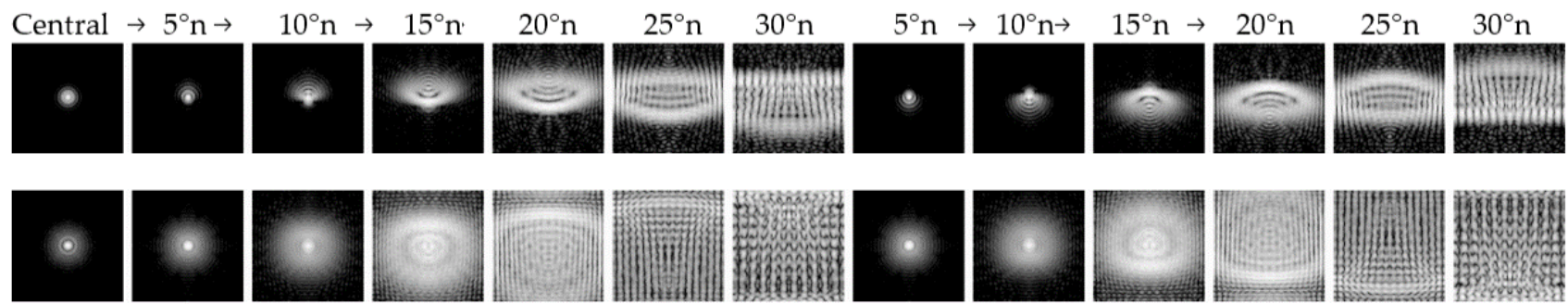

Figure 10. Simulated retinal image quality from central up to $30^{\circ}$ nasal and temporal. (Top row): Proclear monofocal. (Bottom row): Proclear multifocal. Viewing distance at $40 \mathrm{~cm}$.

Table 2. Strehl ratio for each eccentricity. Row one and two are for a viewing distance at infinity and row three and four for a viewing distance at $40 \mathrm{~cm}$. Because we used a rotationally symmetric eye model, the Strehl ratio for nasal and temporal eccentricity are equal.

\begin{tabular}{ccccc}
\hline Eccentricity & $\begin{array}{c}\text { Proclear Monofocal } \\
\text { Infinity }\end{array}$ & $\begin{array}{c}\text { Proclear Multifocal } \\
\text { Infinity }\end{array}$ & $\begin{array}{c}\text { Proclear Monofocal } \\
\mathbf{4 0} \mathbf{~ c m ~}\end{array}$ & $\begin{array}{c}\text { Proclear Multifocal } \\
\mathbf{4 0} \mathbf{c m}\end{array}$ \\
\hline Central & 0.701 & 0.027 & 0.008 & 0.161 \\
$5^{\circ}$ & 0.390 & 0.035 & 0.009 & 0.045 \\
$10^{\circ}$ & 0.042 & 0.017 & 0.009 & 0.021 \\
$15^{\circ}$ & 0.016 & 0.020 & 0.015 & 0.018 \\
$20^{\circ}$ & 0.015 & 0.012 & 0.015 & 0.028 \\
$25^{\circ}$ & 0.011 & 0.016 & 0.015 & 0.021 \\
$30^{\circ}$ & 0.011 & 0.023 & 0.012 & 0.019 \\
\hline
\end{tabular}

\section{Discussion}

Studies show an effect of retarding myopia progression in children using optical therapies, such as simultaneous myopic defocus $[16,18,28]$ or introducing relative peripheral myopia to the retina [29]. However, through both correction methods, it is not clear how the eye detects a myopic defocus, central or peripheral, and how strong in diopters such a defocus should be. In this work, we address two research questions. First, how does accommodation change in young non-presbyopic participants; and second, what does the optical ray-tracing simulation look like on the retina through an eye wearing a multifocal contact lens?

\subsection{Accommodation}

Accommodation response is related with age. Young children can change the refractive power of the crystalline lens much more than older people [30]. However, studies for myopia control in children show that accommodation response does not change when children wear multifocal contact lenses [18] or use monovision [22] (one eye wearing distance correction and the contralateral eye wearing near correction). In our study we used participants aged $24.03 \pm 2.73$. At this age accommodation ability is still sufficient to perform near tasks without any help from an optical near addition such as a multifocal contact lens. With the retina exposed to a simultaneous myopic defocus in the form of 
the Proclear multifocal contact lens, our subject accommodated +1.40 D (95\%CI 1.22/1.57 D), while the accommodation with the monofocal distance correction lens was $+1.97 \mathrm{D}$ $(95 \%$ CI 1.78/2.16 D). The accommodation demand for a target placed at a $40 \mathrm{~cm}$ distance equated to $+2.50 \mathrm{D}$; therefore, in both cases, a lag of accommodation was present. With the monofocal contact lens, our measured accommodation lag was in agreement with a recent study that measured the lag of accommodation in real time in young adults [31]. A lag of accommodation is often present in myopic subjects [32], and is measured by others in subjects wearing multifocal contact lenses [33]. A lag of accommodation is suggested as a potential risk factor for myopia [34] and may stimulate the progression of myopia, although a relationship between the lag of accommodation and myopia progression over time could not be established in [35]. With the hypothesis that hyperopic defocus is a myopia promoter and a myopic defocus is an inhibitor of myopia progression [36], the effect of a reduced accommodation with multifocal contact lenses could mean that it lowers the potential therapeutic effect of slowing myopia progression with multifocal contact lenses. Thus, if the subjects reduced their accommodation accuracy with multifocal contact lenses [37,38], this would result in central/foveal hyperopic defocus. This kind of optical treatment could be more successful if no lag of accommodation was present. We found a difference in accommodation of $0.576 \pm 0.36 \mathrm{D}$ between monofocal and multifocal lenses. This could have been influenced by the measurement protocol. As shown by others [39], it is complex to achieve an objective measure of the accommodation with a multifocal contact lens in place. The variability of the optical power over the participant pupil area can lead to an over- or underestimation of the measurement.

However, short-term [33] and long-term [40] results in patients using a simultaneous myopic defocus contact lens for the purpose of controlling the progression of myopia indicated no negative side effects in terms of the accommodation performance, compared to single-vision contact lenses.

The size of the pupil diameter is linked to the accommodation status and age [41]. The size of the pupil is also influenced by mental and cognitive work [42]. With accommodation, it is known that the pupil becomes smaller. Therefore, the change in pupil size can be used as an indirect control of accommodation during visual tasks. In our population we measured a reduction in pupil diameter during near tasks, as expected. We did not find a difference between male and female pupil size, although our sample size was too small to make a general comment on this aspect.

\subsection{Peripheral Refraction and Image Quality}

Our ray-tracing-generated result of peripheral refraction showed a relative myopic peripheral refraction in both distance and near vision for both monofocal and multifocal contact lenses. Peripheral refraction is hypothesized to play an important role in the process of emmetropization, and animal models of myopia $[43,44]$ deliver evidence for this hypothesis. However, this effect is not always found in chicken models of myopia [45]. It appears that the effect of the peripheral refraction on myopia inhibition depends on the retinal location, which should be relatively central [46]. A recent publication showed the highest effect in monkeys when the central unrestricted vision was small $\left(1.5^{\circ}, 5.8^{\circ}\right.$, or $9.8^{\circ}$, respectively) and the periphery was exposed to a simultaneous defocus $(+3.00$ D) $[42,47]$. The strength of the effect increased when the central unrestricted part of vision decreased in size. The lens with $9.8^{\circ}$ of unrestricted vision still showed a statistically significant shortening of the vitreous body, but the data showed a large variation, with approximately half of the monkeys showing the opposite effect. In humans, a longitudinal study [48] investigated the change in the peripheral refraction and the risk of developing myopia as very little $(-0.024 \mathrm{D}$ per year more myopia per $1 \mathrm{D}$ peripheral hyperopia), but a significant risk of myopia for certain ethnicities, with Asian people exposed to the highest risk. With the Proclear multifocal contact lens, which was used for myopia control [24], we found a simulated myopic peripheral refraction outside the central $12^{\circ}$ for distance and $24^{\circ}$ for near vision (Figures 6 and 8 ). Our simulation in the periphery opposed an in situ 
measurement of peripheral refraction [13]; this study found a relative hyperopic peripheral refraction with the same multifocal contact lens. However, Lopes-Fereira et al. [29] used the same autorefractor and the same contact lens as Ticak and Walline (2013) but found a relative myopic peripheral refraction in their participant. This may indicate the variation and precision of peripheral refraction measures in practice. Our simulated peripheral refraction data show even more peripheral myopia. Surprisingly, for the monofocal Proclear contact lens, our simulation also showed a myopic peripheral refraction outside the central $12^{\circ}$ (distance) and $24^{\circ}$ (near). This counter-intuitive effect of a myopic peripheral refraction with a monofocal contact lens was also found by Bachhouse et al (2012). who measured the peripheral refraction in practice with an open-field autorefractor in university students $[49,50]$. With monofocal contact lenses, there was no report of influencing the progression of myopia; therefore, such a finding was in conflict with the hypothesis that a relative myopic defocus has an inhibitory effect on myopia progression. The obvious change in peripheral refraction with orthokeratology [14,51], from relatively hyperopic to relatively myopic, is generally thought to be responsible for the effect of slowing down the progression of myopia in children when they are treated with orthokeratology contact lenses [52-57]. On the basis of the peripheral refraction hypothesis, which extends back many years [58], and the promising results with orthokeratology and the evidence from animal models, new optical treatment options based on changing the peripheral refraction were developed, especially spectacle lenses $[59,60]$. These optical treatments had a slowing effect on the progression of myopia, but the change in peripheral refraction responsible for this effect is not fully understood. The axial length measured prospectively in a paired-eye study using standard orthokeratology in one eye and multifocal orthokeratology, showed significantly less axial length elongation in the eye fitted with multifocal orthokeratology, but with no significant difference in the peripheral refraction change between the two lenses in children [20]. Additional longitudinal studies have so far not been able to correlate the progression of myopia in humans with a change in the peripheral refraction in children [61,62].

Based on our generated point-spread function, blur could also be a factor that prompts the eye to change its growth response. The used and modified Gullstrand eye showed a high Strehl ratio of 0.701 with the monofocal lens, for viewing at infinity and a reduced Strehl ratio with the multifocal lens of 0.027. A Gullstrand eye model depends on the pupil size, with a Strehl ratio of 0.938 to 0.017 [63]. The receptors in the retina which detect blur and decode the blur sign (myopic or hyperopic) have yet to be discovered, but we know that there is such a mechanism because the eye reacts quickly, defocusing with a swelling or deswelling of the choroid in animals [64] and humans [65,66]. It appears that the mechanism that prompts the eye to respond to a defocus (central or peripheral) is more complex than it appears when reporting peripheral refraction results based on the power vectors [67]. We did not measure the peripheral refraction in our participants. We reported ray-tracing-generated figures in the peripheral refraction. In our study, this was intended to visualize the effect of monofocal and multifocal contact lenses. We used a modified Gullstand eye which was symmetrical, and thus did not represent real data of the eyes of our participants. Therefore, those data should be interpreted more as a description of what the peripheral optics could look like based on Snell's law.

\section{Conclusions}

We showed that non-presbyopic participants accommodated approximately 0.50 less $\mathrm{D}$ when using a multifocal contact lens. Therefore, it can be hypothesized that the positive effect of the use of multifocal contacts on the slowing of myopia progression was not initiated by gross changes to accommodation. Optical ray-tracing simulation showed no change in the peripheral refraction between multifocal and monofocal contact lenses, but showed a clear retinal image degradation with multifocal contact lenses.

Supplementary Materials: The following are available online at https: / www.mdpi.com/article / 10.3390/opt2040019/s1. 
Author Contributions: Conceptualization, M.L.; methodology, A.F., C.G. and M.L.; formal analysis, M.L. and D.E.; investigation, A.F. and C.G.; resources, M.L.; data, M.L., A.F. and C.G.; writingoriginal draft preparation, M.L.; writing—review and editing, M.L.; visualization. D.E.; supervision, M.L.; project administration, A.F. and C.G.; funding acquisition, M.L. All authors have read and agreed to the published version of the manuscript.

Funding: This research received no external funding.

Institutional Review Board Statement: The study adhered to the tenets of the Declaration of Helsinki, received approval from the Northwestern Switzerland Health Ethics Committee (Approval No. 2019-00329), and was prospectively registered with National Clinical Trial Registry (BASEC).

Informed Consent Statement: Participants gave written consent to participate.

Data Availability Statement: Data are available by reasonable request through the corresponding author.

Conflicts of Interest: The authors declare no conflict of interest.

\section{References}

1. Wang, J.; Li, Y.; Musch, D.C.; Wei, N.; Qi, X.; Ding, G.; Li, X.; Li, J.; Song, L.L.; Zhang, Y.; et al. Progression of Myopia in School-Aged Children After COVID-19 Home Confinement. JAMA Ophthalmol. 2021, 139, 293-300. [CrossRef] [PubMed]

2. Williams, K.; Verhoeven, V.M.; Cumberland, P.; Bertelsen, G.; Wolfram, C.; Buitendijk, G.S.; Hofman, A.; van Duijn, C.M.; Vingerling, J.R.; Kuijpers, R.W.A.M.; et al. Prevalence of refractive error in Europe: The European Eye Epidemiology (E3) Consortium. Eur. J. Epidemiol. 2015, 30, 305-315. [CrossRef] [PubMed]

3. Pan, C.-W.; Zheng, Y.-F.; Anuar, A.R.; Chew, M.; Gazzard, G.; Aung, T.; Cheng, C.-Y.; Wong, T.Y.; Saw, S.-M. Prevalence of Refractive Errors in a Multiethnic Asian Population: The Singapore Epidemiology of Eye Disease Study. Investig. Ophthalmol. Vis. Sci. 2013, 54, 2590-2598. [CrossRef]

4. Yam, J.C.; Jiang, Y.; Tang, S.M.; Law, A.K.P.; Chan, J.J.; Wong, E.; Young, A.L.; Tham, C.C.; Chen, L.J.; Pang, C.P. Low-Concentration Atropine for Myopia Progression (LAMP) Study: A Randomized, Double-Blinded, Placebo-Controlled Trial of 0.05\%, 0.025\%, and 0.01\% Atropine Eye Drops in Myopia Control. Ophthalmology 2019, 126, 113-124. [CrossRef]

5. Fang, Y.T.; Chou, Y.J.; Pu, C.; Lin, P.J.; Liu, T.L.; Huang, N.; Chou, P. Prescription of atropine eye drops among children diagnosed with myopia in Taiwan from 2000 to 2007: A nationwide study. Eye 2013, 27, 418-424. [CrossRef]

6. Chia, A.; Chua, W.H.; Wen, L.; Fong, A.; Goon, Y.Y.; Tan, D. Atropine for the Treatment of Childhood Myopia: Changes after Stopping Atropine $0.01 \%, 0.1 \%$ and $0.5 \%$. Am. J. Ophthalmol. 2013, 3, 00642-00649. [CrossRef]

7. Chia, A.; Chua, W.-H.; Cheung, Y.-B.; Wong, W.-L.; Lingham, A.; Fong, A.; Tan, D. Atropine for the Treatment of Childhood Myopia: Safety and Efficacy of $0.5 \%, 0.1 \%$, and $0.01 \%$ Doses (Atropine for the Treatment of Myopia 2). Ophthalmology 2012, 119, 347-354. [CrossRef]

8. Khanal, S.; Phillips, J.R. Which low-dose atropine for myopia control? Clin. Exp. Optom. 2020, 103, 230-232. [CrossRef]

9. Cooper, J.; Eisenberg, N.; Schulman, E.; Wang, F.M. Maximum Atropine Dose Without Clinical Signs or Symptoms. Optom. Vis. Sci. 2013. Publish Ahead of Print. [CrossRef] [PubMed]

10. Jin, J.-X.; Hua, W.-J.; Jiang, X.; Wu, X.-Y.; Yang, J.-W.; Gao, G.-P.; Fang, Y.; Pei, C.L.; Wang, S.; Zhang, J.Z.; et al. Effect of outdoor activity on myopia onset and progression in school-aged children in northeast china: The sujiatun eye care study. BMC Ophthalmol. 2015, 15, 73. [CrossRef]

11. Rose, K.A.; Morgan, I.G.; Ip, J.; Kifley, A.; Huynh, S.; Smith, W.; Mitchell, P. Outdoor activity reduces the prevalence of myopia in children. Ophthalmology 2008, 115, 1279-1285. [CrossRef]

12. Torii, H.; Kurihara, T.; Seko, Y.; Negishi, K.; Ohnuma, K.; Inaba, T.; Kawashima, M.; Jiang, X.Y.; Kondo, S.; Miyauchi, M. Violet Light Exposure Can Be a Preventive Strategy Against Myopia Progression. EBioMedicine 2017, 15, 210-219. [CrossRef]

13. Ticak, A.; Walline, J.J. Peripheral optics with bifocal soft and corneal reshaping contact lenses. Optom. Vis. Sci. 2013, 90, 3-8. [CrossRef] [PubMed]

14. Kang, P.; Swarbrick, H. Peripheral refraction in myopic children wearing orthokeratology and gas-permeable lenses. Optom. Vis. Sci. 2011, 88, 476-482. [CrossRef] [PubMed]

15. Atchison, D.A.; Rosen, R. The Possible Role of Peripheral Refraction in Development of Myopia. Optom. Vis. Sci. 2016, 93, 1042-1044. [CrossRef] [PubMed]

16. Chamberlain, P.; Peixoto-de-Matos, S.C.; Logan, N.S.; Ngo, C.; Jones, D.; Young, G. A 3-year Randomized Clinical Trial of MiSight Lenses for Myopia Control. Optom. Vis. Sci. 2019, 96, 556-567. [CrossRef] [PubMed]

17. Li, S.M.; Kang, M.T.; Wu, S.S.; Meng, B.; Sun, Y.Y.; Wei, S.F.; Liu, L.; Peng, X.X.; Chen, Z.; Zhang, F.J.; et al. Studies using concentric ring bifocal and peripheral add multifocal contact lenses to slow myopia progression in school-aged children: A meta-analysis. Ophthalmic Physiol. Opt. 2017, 37, 51-59. [CrossRef] [PubMed]

18. Anstice, N.S.; Phillips, J.R. Effect of dual-focus soft contact lens wear on axial myopia progression in children. Ophthalmology 2011, 118, 1152-1161. [CrossRef] [PubMed] 
19. Aller, T.A.; Wildsoet, C. Bifocal soft contact lenses as a possible myopia control treatment: A case report involving identical twins. Clin. Exp. Optom. 2008, 91, 394-399. [CrossRef] [PubMed]

20. Loertscher, M.; Backhouse, S.; Phillips, J.R. Multifocal Orthokeratology versus Conventional Orthokeratology for Myopia Control: A Paired-Eye Study. J. Clin. Med. 2021, 10, 447. [CrossRef]

21. Kim, E.; Bakaraju, R.C.; Ehrmann, K. Power Profiles of Commercial Multifocal Soft Contact Lenses. Optom. Vis. Sci. 2017, 94, 183-196. [CrossRef] [PubMed]

22. Phillips, J.R. Monovision slows juvenile myopia progression unilaterally. Br. J. Ophthalmol. 2005, 89, 1196-1200. [CrossRef] [PubMed]

23. Llorente-Guillemot, A.; Garcia-Lazaro, S.; Ferrer-Blasco, T.; Perez-Cambrodi, R.J.; Cervino, A. Visual performance with simultaneous vision multifocal contact lenses. Clin. Exp. Optom. 2012, 95, 54-59. [CrossRef] [PubMed]

24. Walline, J.J.; Greiner, K.L.; McVey, M.E.; Jones-Jordan, L.A. Multifocal contact lens myopia control. Optom. Vis. Sci. 2013, 90, 1207-1214. [CrossRef] [PubMed]

25. Seidemann, A.; Schaeffel, F. An evaluation of the lag of accommodation using photorefraction. Vis. Res. 2003, 43, 419-430. [CrossRef]

26. Schaeffel, F.; Farkas, L.; Howland, H.C. Infrared photoretinoscope. Appl. Opt. 1987, 26, 1505-1509. [CrossRef] [PubMed]

27. Tarrant, J.; Severson, H.; Wildsoet, C.F. Accommodation in emmetropic and myopic young adults wearing bifocal soft contact lenses. Ophthalmic Physiol. Opt. J. Br. Coll. Ophthalmic Opt. Optom. 2008, 28, 62-72. [CrossRef]

28. Lam, C.S.; Tang, W.C.; Tse, D.Y.; Tang, Y.Y.; To, C.H. Defocus Incorporated Soft Contact (DISC) lens slows myopia progression in Hong Kong Chinese schoolchildren: A 2-year randomised clinical trial. Br. J. Ophthalmol. 2014, 98, 40-45. [CrossRef]

29. Lopes-Ferreira, D.; Ribeiro, C.; Neves, H.; Faria-Ribeiro, M.; Queirós, A.; Villa-Collar, C.; Jorge, J.; González-Méijomea, J.M. Peripheral refraction with dominant design multifocal contact lenses in young myopes. J. Optom. 2013, 6, 85-94. [CrossRef]

30. Duane, A. Normal Values of the accommodation at all ages. J. Am. Med Assoc. 1912, LIX, 1010-1013. [CrossRef]

31. Ghoushchi, V.P.; Mompeán, J.; Prieto, P.M.; Artal, P. Binocular dynamics of accommodation, convergence, and pupil size in myopes. Biomed. Opt. Express 2021, 12, 3282-3295. [CrossRef]

32. Gwiazda, J.; Thorn, F.; Bauer, J.; Held, R. Myopic children show insufficient accommodative response to blur. Investig. Ophthalmol. Vis. Sci. 1993, 34, 690-694.

33. Kang, P.; Wildsoet, C.F. Acute and short-term changes in visual function with multifocal soft contact lens wear in young adults. Contact Lens Anterior Eye 2016, 39, 133-140. [CrossRef] [PubMed]

34. Gwiazda, J.E.; Hyman, L.; Norton, T.T.; Hussein, M.E.M.; Marsh-Tootle, W.; Manny, R.; Wang, Y.; Everett, D. Accommodation and Related Risk Factors Associated with Myopia Progression and Their Interaction with Treatment in COMET Children. Investig. Ophthalmol. Vis. Sci. 2004, 45, 2143-2151. [CrossRef] [PubMed]

35. Berntsen, D.A.; Sinnott, L.T.; Mutti, D.O.; Zadnik, K. Accommodative lag and juvenile-onset myopia progression in children wearing refractive correction. Vision Res. 2011, 51, 1039-1046. [CrossRef] [PubMed]

36. Smith, E.L., 3rd; Hung, L.F.; Arumugam, B. Visual regulation of refractive development: Insights from animal studies. Eye 2013, 13, 277. [CrossRef]

37. Wagner, S.; Schaeffel, F.; Troilo, D. Changing accommodation behaviour during multifocal soft contact lens wear using auditory biofeedback training. Sci. Rep. 2020, 10, 5018. [CrossRef]

38. Gong, C.R.; Troilo, D.; Richdale, K. Accommodation and Phoria in Children Wearing Multifocal Contact Lenses. Optom. Vis. Sci. 2017, 94, 353-360. [CrossRef]

39. Altoaimi, B.H.; Almutairi, M.S.; Kollbaum, P.S.; Bradley, A. Accommodative Behavior of Young Eyes Wearing Multifocal Contact Lenses. Optom. Vis. Sci. 2018, 95, 416-427. [CrossRef]

40. Ruiz-Pomeda, A.; Perez-Sanchez, B.; Canadas, P.; Prieto-Garrido, F.L.; Gutierrez-Ortega, R.; Villa-Collar, C. Binocular and accommodative function in the controlled randomized clinical trial MiSight(R) Assessment Study Spain (MASS). Graefes. Arch. Clin. Exp. Ophthalmol. 2018, 257, 207-215. [CrossRef]

41. Guillon, M.; Dumbleton, K.; Theodoratos, P.; Gobbe, M.; Wooley, C.B.; Moody, K. The Effects of Age, Refractive Status, and Luminance on Pupil Size. Optom. Vis. Sci. 2016, 93, 1093-1100. [CrossRef] [PubMed]

42. van der Wel, P.; van Steenbergen, H. Pupil dilation as an index of effort in cognitive control tasks: A review. Psychon. Bull. Rev. 2018, 25, 2005-2015. [CrossRef] [PubMed]

43. Benavente-Perez, A.; Nour, A.; Troilo, D. The effect of simultaneous negative and positive defocus on eye growth and development of refractive state in marmosets. Investig. Ophthalmol. Vis. Sci. 2012, 53, 6479-6487. [CrossRef] [PubMed]

44. Smith, E.L., III; Ramamirtham, R.; Qiao-Grider, Y.; Hung, L.-F.; Huang, J.; Kee, C.-S.; Coats, D.; Paysse, E. Effects of Foveal Ablation on Emmetropization and Form-Deprivation Myopia. Investig. Ophthalmol. Vis. Sci. 2007, 48, 3914-3922. [CrossRef] [PubMed]

45. Schippert, R.; Schaeffel, F. Peripheral defocus does not necessarily affect central refractive development. Vis. Res. 2006, 46, 3935-3940. [CrossRef]

46. Tepelus, T.C.; Vazquez, D.; Seidemann, A.; Uttenweiler, D.; Schaeffel, F. Effects of lenses with different power profiles on eye shape in chickens. Vis. Res. 2012, 54, 12-19. [CrossRef]

47. Smith Iii, E.L.; Arumugam, B.; Hung, L.-F.; She, Z.; Beach, K.; Sankaridurg, P. Eccentricity-dependent effects of simultaneous competing defocus on emmetropization in infant rhesus monkeys. Vis. Res. 2020, 177, 32-40. [CrossRef] 
48. Mutti, D.O.; Sinnott, L.T.; Mitchell, G.L.; Jones-Jordan, L.A.; Moeschberger, M.L.; Cotter, S.A.; Kleinstein, R.N.; Manny, R.E.; Twelker, J.D.; Zadnik, K.; et al. Relative peripheral refractive error and the risk of onset and progression of myopia in children. Investig. Ophthalmol. Vis. Sci. 2011, 52, 199-205. [CrossRef]

49. Kwok, E.; Patel, B.; Backhouse, S.; Phillips, J.R. Peripheral Refraction in High Myopia with Spherical Soft Contact Lenses. Optom. Vis. Sci. 2012, 89, 263-270. [CrossRef]

50. Backhouse, S.; Fox, S.; Ibrahim, B.; Phillips, J.R. Peripheral refraction in myopia corrected with spectacles versus contact lenses. Ophthalmic. Physiol. Opt. 2012, 32, 294-303. [CrossRef]

51. Pauné, J.; Fonts, S.; Rodríguez, L.; Queirós, A. The Role of Back Optic Zone Diameter in Myopia Control with Orthokeratology Lenses. J. Clin. Med. 2021, 10, 336. [CrossRef] [PubMed]

52. Santodomingo-Rubido, J.; Villa-Collar, C.; Gilmartin, B.; Gutierrez-Ortega, R. Myopia control with orthokeratology contact lenses in Spain: Refractive and biometric changes. Investig. Ophthalmol. Vis. Sci. 2012, 53, 5060-5065. [CrossRef] [PubMed]

53. Cho, P.; Cheung, S.W. Retardation of Myopia in Orthokeratology (ROMIO) Study: A 2-year randomized clinical trial. Investig. Ophthalmol. Vis. Sci. 2012, 53, 7077-7085. [CrossRef] [PubMed]

54. Kakita, T.; Hiraoka, T.; Oshika, T. Influence of overnight orthokeratology on axial length elongation in childhood myopia. Investig. Ophthalmol. Vis. Sci. 2011, 52, 2170-2174. [CrossRef] [PubMed]

55. Charm, J.; Cho, P. High myopia-partial reduction orthokeratology (HM-PRO) study: Recruitment and one year result. Contact Lens Anterior Eye 2011, 34 (Suppl. 1), S3. [CrossRef]

56. Walline, J.J.; Holden, B.A.; Bullimore, M.A.; Rah, M.J.; Asbell, P.A.; Barr, J.T.; Caroline, P.J.; Cavanagh, P.J.; Despotidis, N.; Desmond, F.; et al. The current state of corneal reshaping. Eye Contact Lens 2005, 31, 209-214. [CrossRef]

57. Cho, P.; Cheung, S.W.; Edwards, M. The longitudinal orthokeratology research in children (LORIC) in Hong Kong: A pilot study on refractive changes and myopic control. Curr. Eye Res. 2005, 30, 71-80. [CrossRef]

58. Rempt, F.; Hoogerheide, J.; Hoogenboom, W.P. Peripheral retinoscopy and the skiagram. Ophthalmologica 1971, 162, 1-10. [CrossRef]

59. Bao, J.; Yang, A.; Huang, Y.; Li, X.; Pan, Y.; Ding, C.; Lim, E.W.; Zheng, J.; Spiegel, D.P.; Drobe, B.; et al. One-year myopia control efficacy of spectacle lenses with aspherical lenslets. Br. J. Ophthalmol. 2021. [CrossRef]

60. Lam, C.S.Y.; Tang, W.C.; Tse, D.Y.; Lee, R.P.K.; Chun, R.K.M.; Hasegawa, K.; Qi, H.; Hatanaka, T.; To, C.H. Defocus Incorporated Multiple Segments (DIMS) spectacle lenses slow myopia progression: A 2-year randomised clinical trial. Br. J. Ophthalmol. 2020, 104, 363. [CrossRef]

61. Radhakrishnan, H.; Allen, P.M.; Calver, R.I.; Theagarayan, B.; Price, H.; Rae, S.; Sailoganathan, A.; O’Leary, D.J. Peripheral refractive changes associated with myopia progression. Investig. Ophthalmol. Vis. Sci. 2013, 54, 1573-1581. [CrossRef]

62. Sng, C.C.A.; Lin, X.Y.; Gazzard, G.; Chang, B.; Dirani, M.; Lim, L.; Selvaraj, P.; Ian, K.; Drobe, B.; Wong, T.-Y.; et al. Change in peripheral refraction over time in Singapore Chinese children. Investig. Ophthalmol. Vis. Sci. 2011, 52, 7880-7887. [CrossRef]

63. Almeida, M.S.d.; Carvalho, L.A. Different schematic eyes and their accuracy to the in vivo eye: A quantitative comparison study. Braz. J. Phys. 2007, 37, 378-387. [CrossRef]

64. Zhu, X.; Park, T.W.; Winawer, J.; Wallman, J. In a Matter of Minutes, the Eye Can Know Which Way to Grow. Investig. Ophthalmol. Vis. Sci. 2005, 46, 2238-2241. [CrossRef]

65. Chiang, S.T.-H.; Chen, T.-L.; Phillips, J.R. Effect of Optical Defocus on Choroidal Thickness in Healthy Adults With Presbyopia. Investig. Ophthalmol. Vis. Sci. 2018, 59, 5188-5193. [CrossRef] [PubMed]

66. Chiang, S.T.-H.; Phillips, J.R.; Backhouse, S. Effect of retinal image defocus on the thickness of the human choroid. Ophthalmic Physiol. Opt. 2015, 35, 405-413. [CrossRef] [PubMed]

67. Mathur, A.; Atchison, D.A. Peripheral refraction patterns out to large field angles. Optom. Vis. Sci. 2013, 90, 140-147. [CrossRef] 